\title{
Numerical simulation of the dynamic recrystallization behaviour in hot precision forging helical gears
}

\author{
Wei Feng ${ }^{1,2}$, Lin Hua ${ }^{2,3}$, Huajie Mao, ${ }^{1, a}$, and Jian $\operatorname{Lan}^{3}$ \\ ${ }^{1}$ School of Materials Science and Engineering, Wuhan University of Technology, Wuhan 430070, \\ China \\ ${ }^{2}$ Hubei Key Laboratory of Advanced Technology of Automotive Parts, Wuhan 430070, China \\ ${ }^{3}$ School of Automotive Engineering, Wuhan University of Technology, Wuhan 430070, China
}

\begin{abstract}
In hot precision forging helical gears, the dynamic recrystallization phenomena will occur, which affect the microstructure of the formed part and in turn decide their mechanical properties. To investigate the effect of deformation temperature on the dynamic recrystallization in hot precision forging helical gears, a three dimensional (3D) finite element (FE) model was created by coupling the thermo-mechanical model with the microstructure evolution model developed based on the hot compressive experimental data of $20 \mathrm{CrMnTiH}$ steel. The hot precision forging process was simulated and the effect laws of the deformation temperature on the microstructure evolution the formed part were investigated. The results show that the dynamic recrystallization volume fraction and the average grain sizes increased with the increasing deformation temperature and the higher deformation temperature is beneficial to dynamic recrystallization and grain refinement.
\end{abstract}

\section{Introduction}

Helical gears are the most widely used transmission component in many industrial fields such as machine, automobile, aeronautics and astronautics due to their high contact ration, smooth transmission [1]. During hot precision forging helical gears, the deformed metal workpiece will subject to some phenomena of microstructure evolution such as dynamic recrystallization (DRX), dynamic recovery (DRV) and grain growth owing to deformation temperature, strain rate and deformation degree [2]. These phenomena will affect the microstructure of the formed part and play an important role in determining the mechanical properties of the deformed product. To obtain the desired properties, it is very important to investigate and understand the effect of deformation process parameters on the microstructure evolution of the formed helical gears so as to control the microstructure. The deformation temperature is a very significant factor that affects the distribution and evolution of the microstructure during hot metal forming process.

At present, many studies have been carried out to improve the form quality of the products by controlling the microstructure evolution. Yanagimoto et al. investigated the microstructure evolution of

\footnotetext{
${ }^{\text {a }}$ Corresponding author: maohj@whut .edu.cn; fengwei@whut .edu.cn
}

This is an Open Access article distributed under the terms of the Creative Commons Attribution License 4.0, which permits unrestricted use, distribution, and reproduction in any medium, provided the original work is properly cited. 


\section{MATEC Web of Conferences}

plain carbon steel product by controlling the cooling during single-pass heavy hot extrusion deformation to achieve the formed product with ultrafine microstructures [3]. Lin et al. simulated microstructure evolution in hot forming process by incorporating mechanism-based microstructure parameters into a viscoplastic flow model to form a set of unified viscoplastic constitutive equations [4]. Li et al. analyzed the behavior of the microstructure evolution of the copper tube to control the properties of the final products during the three-roll planetary rolling [5].

$20 \mathrm{CrMnTiH}$ steel is a low-carbon steel widely used as a gear material in China due to its high hardenability, anti-wear properties [6,7]. Feng et al. investigated the high temperature deformation behavior and formulated the peak flow stress constitutive equation and the dynamic recrystallization mathematical models of $20 \mathrm{CrMnTiH}$ steel by means of regression analysis based on the hot compression experiment and studied the microstructure evolution laws and the effects of deformation temperature on the microstructure evolution by combining the micrographs analysis with FEM [8,9]. However, few works were conducted to study the microstructure evolution during the hot precision forging helical gears of 20CrMnTiH steel. The purpose of this study is to understand the microstructure evolution law and the effect law of deformation temperature on the microstructure evolution of hot forged helical gears in order to control the fine microstructure and decide the optimum process parameters. A three dimensional finite element (FE) model was built by coupling the thermo-mechanical model with the microstructure evolution model developed based on the hot compressive experimental data of $20 \mathrm{CrMnTiH}$ steel. Based on the FE model, the behavior of microstructure evolution and the effects of deformation temperature on the dynamic recrystallization for the formed part were investigated through simulating the hot precision forging the helical gears.

\section{FE modelling of microstructure evolution in hot precision forging helical gears}

During the hot precision forging the helical gears, the metal is subjected to plastic deformation, heat exchange and microstructure evolution, and there exist a mutual coupling relationship among them. To study the effect of deformation temperature on the dynamic recrystallization in hot precision forging helical gears, it is very important to build up a 3D FE model by coupling the thermo-mechanical model with the microstructure evolution model.

According to the author's previous research, the entire constitutive equations for microstructure evolution of $20 \mathrm{CrMnTiH}$ steel were formulated based on the hot compression experiment as follows [10]:

a) The critical strain model

$$
\begin{gathered}
\varepsilon_{c}=0.8 \varepsilon_{p} \\
\varepsilon_{p}=1.3615 \times 10^{-2} \dot{\varepsilon}^{0.1784} \exp (34370.81 / R T)
\end{gathered}
$$

where $\varepsilon_{c}$ is the critical strain, $\varepsilon_{p}$ is the peak strain, $\dot{\varepsilon}$ the strain rate $\left(\mathrm{s}^{-1}\right), R$ is the universal gas constant (8.314 $\left.\mathrm{J} \mathrm{mol}^{-1} \mathrm{~K}^{-1}\right), T$ is the deformation temperature $(\mathrm{K})$.

b) The dynamic recrystallization kinetics model

$$
\begin{gathered}
X_{\text {drex }}=1-\exp \left[-1.427\left(\frac{\varepsilon-\varepsilon_{c}}{\varepsilon_{0.5}}\right)^{3.419}\right] \\
\varepsilon_{0.5}=3.319 \times 10^{-3} \dot{\varepsilon}^{0.2347} \exp (55315.24 / R T) \\
D_{\text {drex }}=2.0664 \times 10^{4} \dot{\varepsilon}^{-0.04587} \exp (-77788.2 / R T)
\end{gathered}
$$




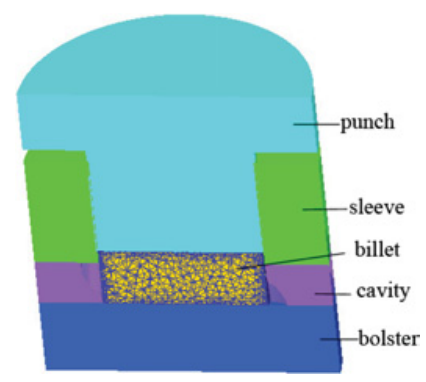

Figure 1. 3D FE model for precision forging helical gear.

where $X_{\text {drex }}$ is the volume fraction of dynamic recrystallization, $\varepsilon_{0.5}$ is the strain of $50 \%$ dynamic recrystallization, $D_{\text {drex }}$ denotes the dynamic recrystallization grain size.

c) The flow stress model

$$
\dot{\bar{\varepsilon}}=7.31 \times 10^{15}[\sinh (0.01244 \bar{\sigma})]^{5.766} \exp [-434591 / R T]
$$

where $\dot{\bar{\varepsilon}}$ and $\bar{\sigma}$ are the effective strain rate and stress, respectively.

The above flow stress model and constitutive equations for microstructure evolution of $20 \mathrm{CrMnTiH}$ steel were implemented into the DEFORM-3D software through the preprocessor. Its relevant mechanical properties and thermal characteristics as follows: Young's moduls E $=212 \mathrm{GPa}$, Poisson's ration $\mu=0.289$, density $\rho=7850 \mathrm{~kg} / \mathrm{m}^{3}$, Thermal expansion $\alpha=1.27 \times 10^{-5} 1 /{ }^{\circ} \mathrm{C}$, Thermal conductivity $\lambda=44\left(\mathrm{~N} / \mathrm{sec} /{ }^{\circ} \mathrm{C}\right)$ and Heat capacity $\mathrm{c}=460\left(\mathrm{~J} / \mathrm{Kg} /{ }^{\circ} \mathrm{C}\right)$.

The helical gear product was formed using the clamping-type closed-die forging. The specification of the helical gear is as follows: number of teeth, normal module, normal pressure angle, helix angle and teeth width is $23,2,20^{\circ} \mathrm{C}, 14{ }^{\circ} \mathrm{C}, 12 \mathrm{~mm}$, respectively. It is also left-handed and a pitch diameter of $47.44 \mathrm{~mm}$ and a root circle diameter of $42.408 \mathrm{~mm}$. Cylindrical billet with the diameter of $42 \mathrm{~mm}$ and height of $15.2 \mathrm{~mm}$ was machined from the rolling bar and meshed around 120000 initial tetrahedral solid elements, and mesh window and automatic remeshing technique were adopted to save computation resources and improve simulation quality during simulation. The friction between the dies and the deformed blank was assumed to be of shear type and the friction factor was set as 0.25 and all the dies are regarded as the rigid body and the billet is the deformed body. The environment temperature is $20^{\circ} \mathrm{C}$ and the convection coefficient to environment is $0.02 \mathrm{~N} / \mathrm{mm} / \mathrm{sec} /{ }^{\circ} \mathrm{C}$ and the heat transfer coefficient between the deformed billet and the die is $5 \mathrm{~N} / \mathrm{mm} / \mathrm{sec} /{ }^{\circ} \mathrm{C}$. The speed of the punch was $5 \mathrm{~mm} / \mathrm{s}$ and the deformation temperatures of the billet are $900^{\circ} \mathrm{C}, 950{ }^{\circ} \mathrm{C}, 1000^{\circ} \mathrm{C}$ and $1050^{\circ} \mathrm{C}$, respectively. The initial grain size of the deformed billet measured is $85 \mu \mathrm{m}$. A 3D FE model by coupling the thermo-mechanical model with the microstructure evolution model for precision forging of the helical gear in DEFORM-3D software is developed, as shown in Fig. 1.

\section{Results and discussion}

\subsection{Distributions of effective strain}

Figure 2 shows the distribution of effective strain at different deformation temperatures during the hot precision forging helical gears. It can be seen from Fig. 2 that the effective strain distribution is very inhomogeneous in the axial and radial directions, while it is homogeneous in the circumferential direction. The plastic deformation is mainly undergone at the addendum and the dedendum, while the other part hardly deforms at different deformation temperatures. 
MATEC Web of Conferences

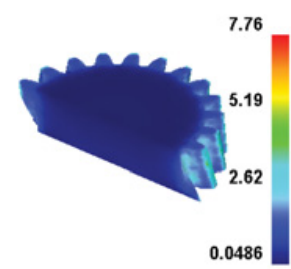

(a) $\mathrm{T}=900^{\circ} \mathrm{C}$

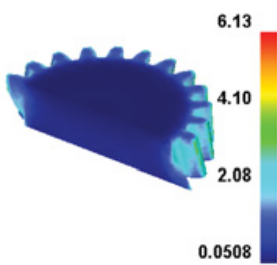

(b) $\mathrm{T}=950^{\circ} \mathrm{C}$

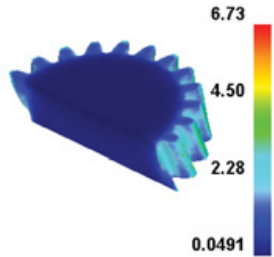

(c) $\mathrm{T}=1000^{\circ} \mathrm{C}$

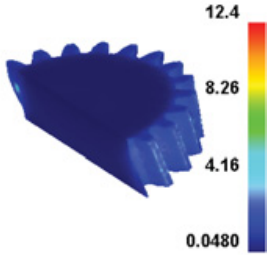

(d) $\mathrm{T}=1050^{\circ} \mathrm{C}$

Figure 2. Distributions of effective strain at different temperatures.
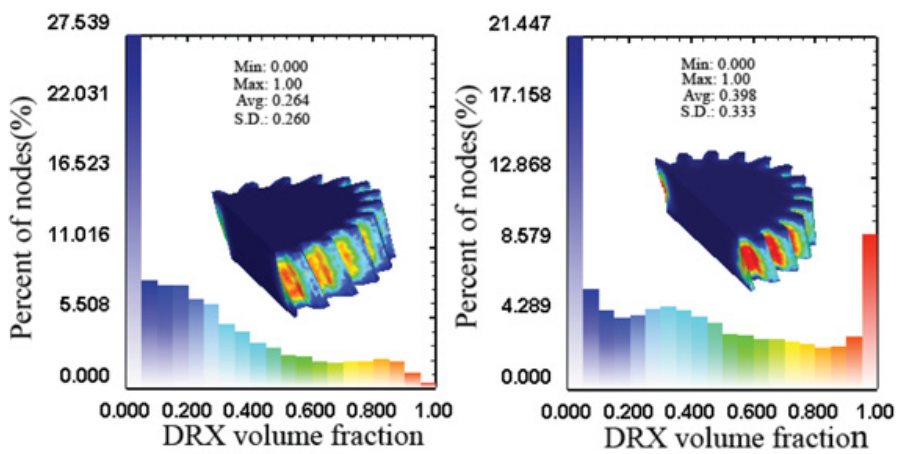

(a) $\mathrm{T}=900^{\circ} \mathrm{C}$

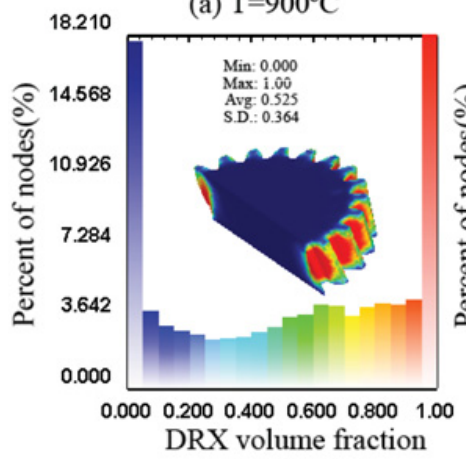

(c) $\mathrm{T}=1000^{\circ} \mathrm{C}$

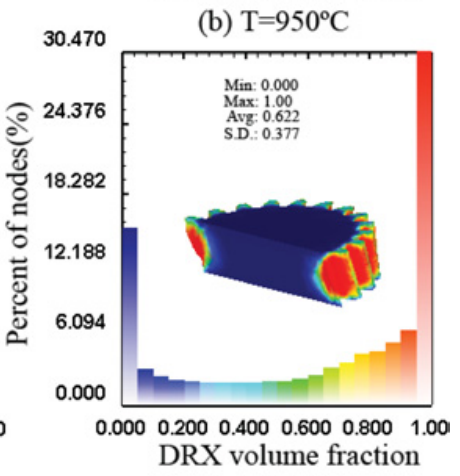

(d) $\mathrm{T}=1050^{\circ} \mathrm{C}$

Figure 3. Distributions of DRX volume fraction at different temperatures.

\subsection{Distributions of dynamic recrystallization volume fraction}

The distributions of dynamic recrystallization volume fraction of the deformed gears for hot precision forging at the different deform temperatures are shown in Fig. 3. It can be seen that the dynamic recrystallization volume fraction is distributed unevenly in the deformed gears. The dynamic recrystallization volume fraction is larger at the addendum and the dedendum, while that is relatively small at the other part and even the value is zero, which illustrates that the dynamic recrystallization doesn't occur in these regions. The results correspond to the distributions of the effective strain as shown in Fig. 2. That is, the large plastic deformation is conductive to occuring dynamic recrystallization. It can be also observed that the dynamic recrystallization volume fraction increases with the increasing deformed temperature. The volume fraction of complete dynamic recrystallization in the deformed gears at the temperature of $900{ }^{\circ} \mathrm{C}, 950{ }^{\circ} \mathrm{C}, 1000^{\circ} \mathrm{C}$ and $1050{ }^{\circ} \mathrm{C}$ is $4.04 \%, 22.4 \%, 38.3 \%$ and 


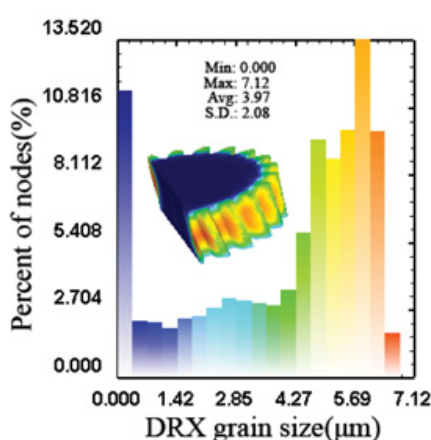

(a) $\mathrm{T}=900^{\circ} \mathrm{C}$

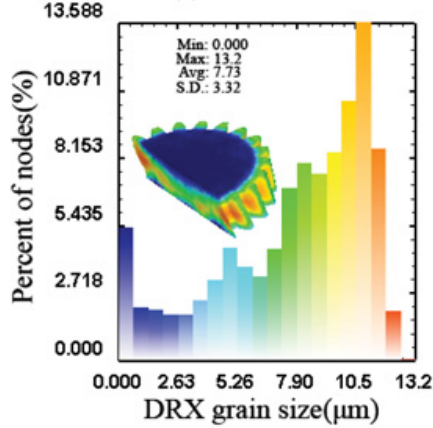

(c) $\mathrm{T}=1000^{\circ} \mathrm{C}$

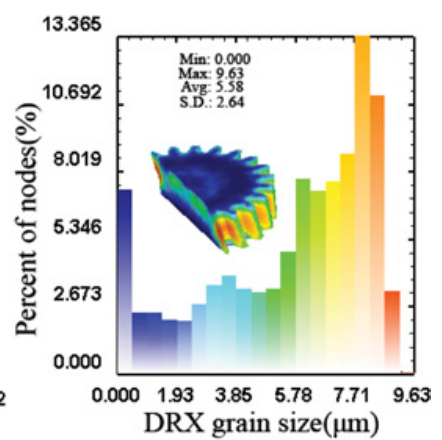

(b) $\mathrm{T}=950^{\circ} \mathrm{C}$

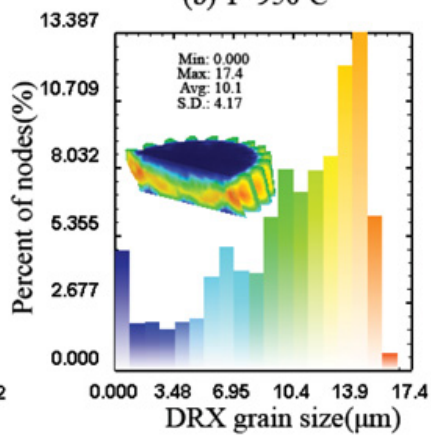

(d) $\mathrm{T}=1050^{\circ} \mathrm{C}$

Figure 4. Distributions of DRX grain size at different temperatures.

$55.9 \%$, respectively. The results show that the dynamic recrystallization is easy to occur when the deformation temperature increased gradually. This is because that the mobility at boundaries for the nucleation and growth of dynamic recrystallization grains are higher with the increasing deformation temperature.

\subsection{Distributions of dynamic recrystallization grain size}

Figure 4 shows the distributions of the dynamic recrystallization grain size of the deformed gears for hot precision forging at the different deform temperatures. It can be found that the dynamic recrystallization grain size of the deformed gear become coarse with the increasing deformed temperature and the distributions aren't also uniform. The maximum dynamic recrystallization grain sizes at the temperature of $900{ }^{\circ} \mathrm{C}, 950{ }^{\circ} \mathrm{C}, 1000^{\circ} \mathrm{C}$ and $1050{ }^{\circ} \mathrm{C}$ are $7.12 \mu \mathrm{m}, 9.63 \mu \mathrm{m}, 13.2 \mu \mathrm{m}$ and $17.4 \mu \mathrm{m}$, respectively. The average dynamic recrystallization grain sizes at the temperature of $900^{\circ} \mathrm{C}, 950{ }^{\circ} \mathrm{C}, 1000{ }^{\circ} \mathrm{C}$ and $1050{ }^{\circ} \mathrm{C}$ are $3.97 \mu \mathrm{m}, 5.58 \mu \mathrm{m}, 7.73 \mu \mathrm{m}$ and $10.1 \mu \mathrm{m}$, respectively. The results show that the grain size grows more quickly when the deformation temperature increases gradually. It can be also observed that the dynamic recrystallization grain locates mostly in the addendum and the dedendum of the final deformed parts, while that is relatively low in the other region. The result shows that the fine grains can be obtained in the large plastic deformation owing to the occurrence of dynamic recrystallization.

\section{Conclusions}

A coupled thermo-deformation-microstructure FE model was developed to simulate the hot precision forging process for helical gears in order to investigate the effect deformation temperature on 


\section{MATEC Web of Conferences}

the microstructure evolution of the final deformed part. The main conclusions can be obtained as follows:

(1) The dynamic recrystallization is easy to happen in the large plastic deformation zone of the addendum and the dedendum, while it hardly takes place in the other region of the deformed gear. The full dynamic recrystallization volume fraction increases with the increasing deformation temperatures.

(2) The distribution of the dynamic recrystallization grain size is not uniform and increases with the increasing deformed temperature. The fine grains are obtained in the large plastic deformation zone of the addendum and the dedendum.

The authors would like to thank the National Natural Science Foundation of China (51475344), the Natural Science Foundation of Hubei Province (2014CFB855), Innovative Research Team Development Program of Ministry of Education of China (IRT13087) and the Key Research and Development Project of New Products and New Technologies of Hubei Province (2012BAA08003) and High-end Talent Leading Program of Hubei Province (201286) for the support given to this research.

\section{References}

[1] W. Feng, L. Hua, X.H. Han, J. Cent. South. Univ., 19, 9 (2012)

[2] C.M. Sellars, J.A. Whiteman, Met. Sci., 13, 8 (1979)

[3] J. Yanagimoto, S. Sugiyama, A. Yanagida, N. Iwamura, M. Ishizuka, J. Mater. Process. Tech., 209, 7 (2009)

[4] J. Lin, T.A. Dean, J. Mater. Process. Tech., 167, 9 (2005)

[5] B. Li, S.H. Zhang, H.Q. Zhang, G.L. Zhang, J. Mater. Eng. Perform., 17, 7 (2008)

[6] X.H. Han, L. Hua, Tribol. Int., 55, 11 (2012)

[7] X.H. Han, L. Hua, W.H. Zhuang, X.C. Zhang, J. Mater. Process. Tech., 214, 15 (2014)

[8] W. Feng, Y.H. Fu, Mater. Des., 57, 7 (2014)

[9] W. Feng, S.T. Wu, AMR, 1095, 5 (2015)

[10] W. Feng, F.J. Xu, J. Plasticity Eng., 21, 7 (2014) (in Chinese) 